ANNALS OF

CLINICAL

NEUROPHYSIOLOGY

\title{
Acute unilateral isolated abducens nerve palsy associated with anti-GM1 immunoglobulin M antibody
}

Hyoshin Son, Ahwon Kim, Sang Bin Hong, and Dae Lim Koo

Department of Neurology, Seoul National University Boramae Medical Center, Seoul National University College

of Medicine, Seoul, Korea

Received: February 8, 2019

Revised: May 29, 2019

Accepted: June 5, 2019

\section{Correspondence to}

\section{Dae Lim Koo}

Department of Neurology, Seoul National University Boramae Medical Center, 20 Boramae-ro 5-gil, Dongjak-gu, Seoul 07061, Korea

Tel: $+82-2-870-2473$

Fax: $+82-2-831-0714$

E-mail:koodaelim@gmail.com

ORCID

\section{Hyoshin Son}

https://orcid.org/0000-0001-6643-3712

\section{Ahwon Kim}

https://orcid.org/0000-0002-1595-1680

Sang Bin Hong

https://orcid.org/0000-0001-8504-291X

Dae Lim Koo

https://orcid.org/0000-0001-6858-6093

Acute ophthalmoparesis that includes the oculomotor, trochlear, or abducens nerve may occur as an initial presentation of Miller Fisher syndrome (MFS). The symptoms of MFS or variant forms of Guillain-Barre syndrome are pathogenically related to anti-GQ1b antibodies. We report a case of a 36-year-old man with unilateral isolated abducens nerve palsy associated with anti-GM1 antibody. To the best of our knowledge, this is the first report of unilateral isolated abducens nerve palsy with positivity for anti-GM1 immunoglobulin M antibody.

Key words: Abducens nerve; Ophthalmoplegia; Immunoglobulins

Acute unilateral ophthalmoparesis is generally associated with structural lesions or cerebrovascular disorders rather than systemic conditions. ${ }^{1}$ Acute ophthalmoparesis is observed in up to $15 \%$ of Guillain-Barre syndrome (GBS) cases, even in the absence of involvement of other peripheral nerves. In patients with the clinical spectrum of Miller Fisher syndrome (MFS) and variant forms of GBS, detecting for the presence of anti-GQ1b antibody (the antibody to ganglioside GQ1 b) is useful for the diagnosis. ${ }^{2}$ Here we report a case of unilateral isolated abducens nerve palsy associated with anti-GM1 antibody without other causes.

\section{CASE}

A 36-year-old man visited the emergency room of our hospital with double vision, which had first appeared 2 days previously. No history of recent infection or medication was reported. The patient reported that his double vision was aggravated during horizontal gaze to the left, which was confirmed in a neurological examination. That examination also revealed complete paralysis in the abductor muscles of the left eye, which suggested

This is an Open Access article distributed under the terms of the Creative Commons Attribution Non-Commercial License /http:// creativecommons.org/licenses/by-nc/4.0) which permits unrestricted non-commercial use, distribution, and reproduction in any medium, provided the original work is properly cited. 
isolated abducens nerve palsy of the left eye. Lancaster tests confirmed the presence of abduction deficit of the left eye (paralytic strabismus) (Fig. 1). Examinations of the motor and sensory functions produced unremarkable findings, and his deep tendon reflexes were normotensive in the upper and lower extremities. Vital signs including the blood pressure, heart rate, and body temperature were within the normal ranges. Normal results were also obtained in laboratory investigations that included the complete blood cell count, electrolytes, thyroid function, C-reactive protein, and anti-acetylcholine-receptor antibody. Nerve conduction studies produced normal values, and a repetitive stimulation test of the facial nerve did not reveal abnormal response decrements. Brain magnetic resonance imaging yielded no abnormal findings. The cerebrospinal fluid values including intrathecal immunoglobulin (lg) G were all within the normal ranges. Assays of antiganglioside antibodies revealed seropositivity for anti-GM1 IgM antibody, but seronegativity for anti-GM1 lgG, anti-GD1 IgM, anti-GD1 lgG, anti-GQ1b IgM, and anti-GQ1b IgG antibodies. Blood-test values for autoantibodies related to vasculitis and demyelinating dis- ease, including antinuclear antibodies, rheumatoid factor, antineutrophil cytoplasmic antibody, and anti-aquaporin-4 antibody, were all within normal ranges. Because the patient's diplopia had not improved 1 week after the symptom onset, a presumptive diagnosis of inflammatory etiology was made. Accordingly, the authors planned to treat the patient with intravenous Ig administration or plasmapheresis. However, the patient declined treatment and was discharged.

\section{DISCUSSION}

Abducens nerve palsy is the most commonly encountered type of extraocular muscle paresis, which can be evoked by insufficient vascular supply, intra-axial tumors around the brainstem, and demyelinating diseases such as MFS and variant forms of $\mathrm{GBS}^{3}$ Patients with MFS can initially present with isolated ophthalmoparesis, particularly that pathogenically related to anti-GQ1b antibodies, and anti-GM1 and anti-GD1b antibodies that have been implicated in the involvement of peripheral motor nerves. GM1 glycoprotein
Right Eye (Red) Deviation during Left Eye Fixation

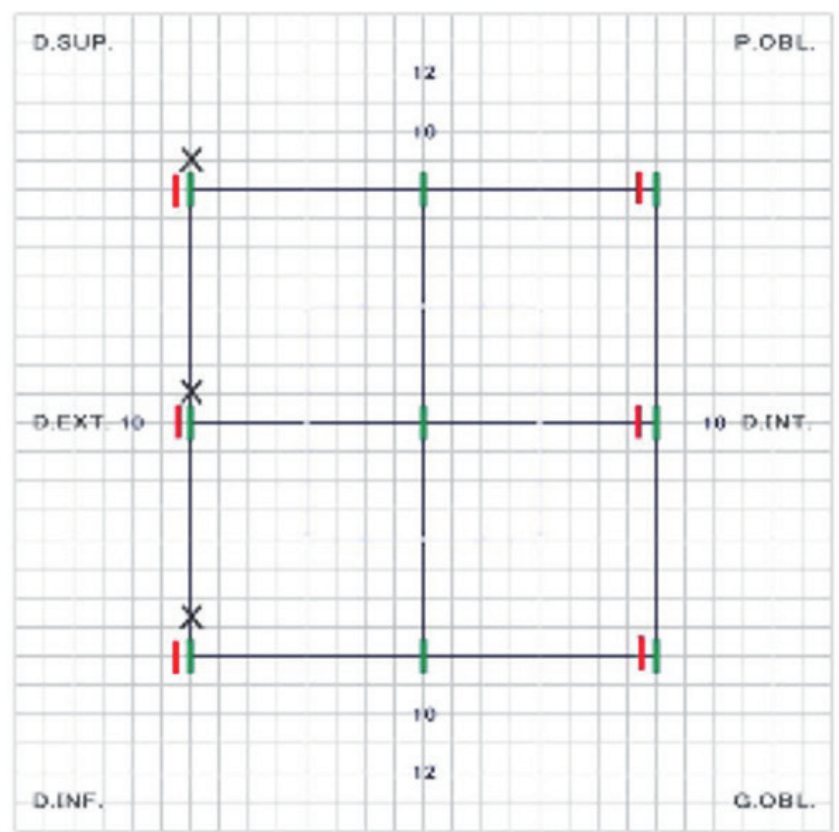

Left Eye (Green) Deviation during Right Eye Fixation

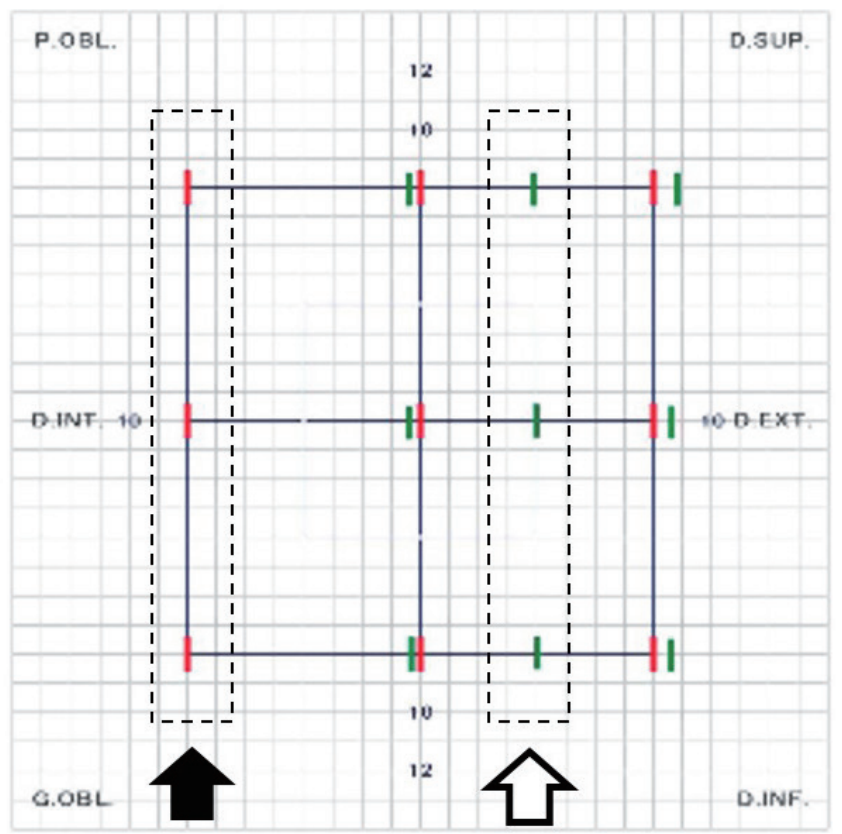

Fig. 1. Isolated abducens nerve palsy of the left eye. Lancaster tests illustrated an isolated abduction deficit of the left eye (paralytic strabismus). Red bars (the dotted line box from closed arrow) indicate normal positions of the right eye during left conjugate gaze. Green bars (the dotted line box from open arrow) represent abnormal positions of the left eye, which are deviated from red bars during left conjugate gaze. 
is present in the axolemma at the nodes of Ranvier and on the myelin of the motor nerves, and so the presence of this antibody is clinically suggestive of the involvement of motor nerves. ${ }^{4}$ Several published reports have described the involvement of cranial nerves in cases with positivity for anti-GM1 antibody, although the significance of GM1 glycoprotein in the pathogenesis of cranial nerve involvement remains unclear. Lower bulbar palsy (dysarthria, tongue discomfort, and tinnitus) or acute ophthalmoparesis involving oculomotor nerve palsy after gastrointestinal infection are reportedly associated with the presence of $\lg G$ or IgM anti-GM1 antibody, respectively. However, those findings were accompanied by other antibodies such as anti-GD1b or anti-GD1a. ${ }^{5-7}$ In a case of isolated abducens nerve paresis, the presence of a higher titer of anti-asialo-GM1 antibody after Campylobacter jejuni enteritis was reported despite negativity for anti-GM1 antibody. ${ }^{8,9}$

It is worth considering the significance of the present case in light of similar previously reported cases. Rare cases of seropositivity for anti-GM1 antibody in acute ophthalmoparesis (as an additional pathophysiological factor) and the role of GM1 glycoprotein and anti-GM1 antibody with involvement of the cranial nerves could be suggested. Our patient was seropositive for anti-GM1 IgM antibody in the absence of anti-GM1 lgG antibody, suggesting an alternative role in the acute phase of the disease course. We applied immunoblot testing to confirm the presence of anti-GM1 antibody. The possibility of false positivity for anti-GM1 antibody should be considered, because a false-positive rate of immunoblot testing for anti-GM1 antibody of $<17 \%$ has been reported previously. ${ }^{10}$ However, it was unfortunate that repeat follow-up testing for anti-GM1 antibody along with other antibodies such as anti-GT1a lgG was not performed (due to the patient's refusal).

To the best of our knowledge, this is the first report of unilateral isolated abducens nerve palsy with positivity for anti-GM1 IgM antibody. The associations of anti-GM1 antibodies and the involvement of the cranial nerves should be investigated further in a larger case series and more laboratory findings. In clinical settings, immunohistochemical tests for the presence of antiganglioside antibodies (including anti-GM1 antibody) could improve the diagnostic accuracy, especially in patients with an unclear clinical history or a lack of evidence for determining the etiology.

\section{Conflicts of Interest}

We have no affiliations with or involvement in any organization or entity with any financial interest, or non-financial interest. The authors report no disclosures.

\section{REFERENCES}

1. Chou KL, Galetta SL, Liu GT, Volpe NJ, Bennett JL, Asbury AK, et al. Acute ocular motor mononeuropathies: prospective study of the roles of neuroimaging and clinical assessment. J Neurol Sci 2004;219:35-39.

2. Odaka M, Yuki N, Hirata K. Anti-GQ1b lgG antibody syndrome: clinical and immunological range. J Neurol Neurosurg Psychiatry 2001;70:50-55.

3. Kaida K, Ariga T, Yu RK. Antiganglioside antibodies and their pathophysiological effects on Guillain-Barre syndrome and related disorders--a review. Glycobiology 2009;19:676-692.

4. Willison HJ, Yuki N. Peripheral neuropathies and anti-glycolipid antibodies. Brain 2002;125(Pt 12):2591-2625.

5. Lavallée P, Vidailhet M, Dussaule JC, Derkinderen P. Post-infectious ophtalmoparesis associated with anti-GM1 but not with anti-GQ1b antibodies. Eur J Neurol 2001;8:475-476.

6. Go T. Partial oculomotor nerve palsy associated with elevated anti-galactocerebroside and anti-GM1 antibodies. J Pediatr 2000;137:425-426.

7. Han TH, Kim DY, Park DW, Moon JH. Transient isolated lower bulbar palsy with elevated serum anti-GM1 and anti-GD1b antibodies during aripiprazole treatment. Pediatr Neurol 2017;66:96-99.

8. Fusco C, Bertani G, Scarano A, Giustina ED. Acute ophthalmoparesis associated with anti-GM1, anti-GD1a, and anti-GD1b antibodies after enterovirus infection in a 6-year-old girl. J Child Neurol 2007;22:432-434.

9. Katchanov J, Lünemann JD, Masuhr F, Meisel A, Möller $H$, Zschenderlein R. Isolated abducens nerve paresis associated with high titer of anti-asialo-GM1 following Campylobacter jejuni enteritis. J Neurol 2004;251:1404-1405.

10. Caudie C, Quittard PA, Bouhour F, Vial C, Garnier L, Fabien $\mathrm{N}$. Comparison of commercial tests for detecting multiple anti-ganglioside autoantibodies in patients with well-characterized immune-mediated peripheral neuropathies. Clin Lab 2013;59:1277-1287. 